\title{
A Reappraisal of the Exchange Rate Determination:
}

\section{A Liquidity Approach}

\author{
Yan Li (Corresponding author) \\ Department of Economics, University of Wisconsin - Eau Claire \\ 105 Garfield Ave. P.O.Box 4004; Eau Claire, WI; 54702-4004, USA \\ Tel: 1-715-836-3507_E-mail: liyan@uwec.edu \\ Xiangming Fang \\ Department of Biostatistics, East Carolina University \\ 2435F Health Sciences Building, Greenville, NC 27858, USA \\ Tel: 1-252-744-6041 E-mail: fangx@ecu.edu
}

\begin{abstract}
A dynamic general-equilibrium model with limited participation in financial markets is constructed to study the determination of nominal exchange rates in a small open economy with tradable and non-tradable goods. The qualitative and quantitative implications of this framework are assessed under flexible prices. Then, the panel dynamic OLS regression is applied to seek the empirical support for this liquidity-exchange rate model, a slight departure from the standard monetary-exchange rate model. The findings in the present paper shed light on the cointegration between the macroeconomic fundamentals and nominal exchange rates.
\end{abstract}

Keywords: Cointegration, Exchange Rate Determination, Liquidity Effects

JEL Codes: F31; F37; F41; F42

Acknowledgements

Yan Li acknowledges the support from the department of Economics at the University of Wisconsin - Eau Claire and appreciates valuable comments from Steve Williamson. Thanks also go to seminar participants at the University of Iowa.

\section{Introduction}

The last two decades have witnessed dramatic innovations in both the theory and the empirical understanding of international finance, with the development of the "New Open Economy Macroeconomics" (NOEM). However, a number of challenges remain. One of the most widely debated and still not-well-answered questions is how nominal exchange rates are determined.

Since the outset of the recent float in the early 1970s, a variety of research avenues for the exchange rate determination have been constructed. Among them, the monetary model remains a dominant paradigm, which suggests a long-run equilibrium relationship among the relative money stocks, the relative income levels and the nominal exchange rates (Frenkel 1976). However, the development of this monetary approach is accompanied with extensive and unresolved debates regarding its empirical validity. Many previous empirical studies have not established sufficient evidence to verify the suggested relationship between the exchange rates and macroeconomic fundamentals.

Meese and Rogoff (1983 a) argue that the conventional monetary-exchange rate models can not significantly outperform a naive random walk in explaining the behavior of nominal exchange rates. This casted a devastating critique of standard monetary models and marked a watershed in exchange rate economics. Then, new methods to test the model are constantly springing up, and the results are mixed. For instance, the cointegration technique is used by MacDonald and Taylor (1993) to examine the validity of the forward-looking monetary exchange rate models. Empirical support was found, but such a test failed on a longer span of data (Sarantis 1994). Recently, the attempt in determining exchange rates through monetary models has seemed to claim more success. By employing a panel of time series data, Mark and Sul (2001) successfully improved the power of the tests. Their results show that variations in monetary fundamentals induce deviations of exchange rates from the equilibrium 
level. Therefore, such co-movement could be used to study the exchange rate dynamics, which restored some hope in the standard monetary model.

Most of the previous research, as mentioned above, mainly relies on the sophistication of econometric techniques to generate statistical evidence in favor of the existing economic theory. However, not much attention has been really directed to the theory itself, the underlying mechanism that governs the exchange rate behavior. Our paper attempts to revisit the benchmark model of exchange rate determination from another perspective. In addition to the aggregate money stock, we will examine the impact of money diffusion on exchange rates in this framework, where monetary policy is introduced by open market operations. Then, we investigate the way in which such a liquidity effect relates to the exchange rate dynamics. To take a closer look at the purchasing power parity (PPP), one of the fundamental building blocks of monetary exchange rate models, we assume in the present paper that the production is endogenized, with two different goods sectors coexisting in each country: the non-tradables and tradables. Therefore, the law of one price is generally broken, even in an environment with flexible prices. Nominal exchange rates are now determined not only through financial transactions, but also through the transactions in the tradable goods market.

Another interesting feature in this environment is how we will model the liquidity effect, the so called distributional effect of monetary policy. To explore the propagation of monetary shocks, two broad classes of models are available in the literature, sticky price and limited participation. In a voluminous recent literature, the sticky price model has become the workhorse of monetary policy analysis in both the closed-economy and open-economy, where the adjustment in prices is sluggish. For instance, Obstfeld and Rogoff (1995), Hau (2002), and Clarida, Gali and Gertlerc (2002). At the same time, some effort has been devoted to limited participation models (liquidity models, hereafter), where monetary policy plays a role in the economy due to its asymmetric distributional effects on economic agents. That is the impact of monetary policy will diffuse gradually in the economy and different economic agents will be affected at different timings. Recent work on liquidity effects in a closed economy was initiated by Grossman and Weiss (1983), and further developed by Lucas (1990) and Fuerst (1992). Then, Schlagenhauf and Wrase (1995), Grilli and Roubini (1996) and Alvarez, Atkeson and Kehoe (2002) extend this line of research to the open-economy settings.

There is no sufficient evidence so far to distinguish the performance of sticky price and liquidity models. In the present paper, we will pursue the "liquidity" path by incorporating the frictions of limited participation into financial markets. Then, a small open economy model is laid out to study the role of liquidity effect in the exchange rate determination. The theoretical results show the cointegration between the nominal exchange rates and an expanded set of macroeconomic fundamentals. The speed at which the additional liquidity diffuses in the economy does affect the exchange rates. Later, a special case of this revised monetary model is tested against a collection of six OECD countries using monthly data running from 1985 to 2005. Specifically, we pool the time series data and then adopt the panel dynamic OLS method proposed by Mark and Sul (2001). The generated statistical evidence lends support to our model.

The remainder of this paper is organized as follows. In Section 2, the theoretical model is laid out. In Section 3, the representative household's problem is characterized and equilibrium conditions are derived. In Section 4, the panel dynamic OLS regression is applied to seek an empirical support for the theoretical model. Section 5 concludes.

\section{The Model}

Consider a world consisting of two countries: Home and Foreign, between which consumption goods are traded. Three types of markets exist in each country, a financial market, a tradable goods and a non-tradable goods markets that open and close sequentially. The two countries are (ex-ante) symmetric. Without loss of generality, we will only describe the Home economy, with the understanding that similar expressions are employed to characterize the Foreign economy. All Foreign variables are denoted with an asterisk.

Each country is inhabited by a unit mass of infinitely lived households. In a given country, each household is specialized in producing some goods but wishes to consume goods that are different from its own products. Therefore, exchange is necessary for consumption. The absence-of-double-coincidence of wants is assumed, which provides a role in this economy for fiat money and credit. A representative household is consisted of a credit buyer, a continuum of financial transactors of mass 2 , a continuum of workers and a continuum of cash shoppers with mass 1, respectively. In particular, the credit buyer dwells at the non-tradable goods market, while the shoppers with cash wonder in the tradable goods market. Each worker is endowed with a flow of one unit of time every period. At any point in time, a worker is either working or enjoying leisure. The heterogenous wealth distribution and endogenized labor supply decision introduce idiosyncratic risks into this model. Following 
Lucas (1990), we group different agents into large households, in which each agent shares the same amount of consumption and regards the household's utility as the common objective. Therefore, idiosyncratic risks across agents are smoothed out within each household. Agents' decision problem can be simplified as a representative household's maximization problem.

\subsection{The Government}

Monetary policies are conducted by the government via open market operations in the model. In period $t$, the government in the Home (Foreign) country chooses the quantity of within-period nominal bonds to issue, denoted by $\bar{B}_{t+1}\left(\bar{B}_{t+1}^{*}\right)$, such that

$\bar{B}_{t+1}=\gamma_{t} \bar{M}_{t}$

$\bar{B}_{t+1}^{*}=\gamma^{*} \bar{M}_{t}^{*}$

for $t=0,1,2,3, \ldots$, where $\bar{M}_{t}\left(\bar{M}_{t}^{*}\right)$ is the quantity of aggregate money balance at the beginning of period $t$ in Home (Foreign) country. Note that $\gamma_{t}\left(\gamma_{t}^{*}\right)$ is a random variable. It indicates the monetary policy instrument of the central bank in the Home (Foreign) country.

The specification of monetary policy is generally controversial. Bernanke and Blinder (1992) argue federal fund rate is superior to monetary aggregate and treasury bill rate in predicating monetary policy. Christiano and Eichenbaum (1992c) claim that innovations to nominal non-borrowed reserves measures the stance of monetary policy well. Walsh (2005) modeled policy shocks with innovations to the nominal interest rate. Williamson (2004), however, identifies the monetary policy by changes in the monetary aggregate. In this paper, we follow Williamson (2004) to focus on monetary policy shocks embodied by a monetary aggregate change, although it is realized that not all changes in monetary aggregate are necessarily caused by monetary policy shocks. The financial market structure in the model is complete and relatively standard in the literature.

\subsection{The Representative Household}

Since the Home and Foreign country are isomorphic, we focus on the behavior of a representative Home household and provide details only for Home households' objective and trading opportunities.

A representative household starts period $t$ with a money balance $M_{t}$, carried from period $t-1$ and consisted of reserve $M_{t}^{r}$ and cash $M_{t}^{c}$. Note that, $M_{t}^{r}$ and $M_{t}^{c}$ are held by a continuum of financial intermediaries, indexed on the interval[ $[0,1]$ and $[1,2]$, respectively. We assume all the financial transactions, such as depositing or withdrawing money from the reserve account with the central bank, can only be carried out by the financial intermediaries in the households.

At the start of period $t$, financial intermediaries indexed on interval $[0,1]$ arrive at the asset market with reserve balance $M_{t}^{r}$. At the same time, the cash-carrying financial transactors on the interval $[1,2]$ take a trip to the tradable goods market and deliver $M_{t}^{c}$ to all cash buyers.

Once financial transactors have left, the two aggregate shocks, the monetary shock $\gamma_{t}$ and the productivity shock $A_{t}$ are revealed, where $\gamma_{t}$ measures the degree of central bank intervention through open market operations. Note that, since cash-holding transactors have already left the household, the household cannot revise its consumption decision about tradable goods according to the changed financial market circumstances. That is, after $\gamma_{t}$ is disclosed, the money allocated for tradable goods is already locked in and cannot be readjusted.

The asset market opens. Bonds denominated in home and foreign currencies are bought and sold there. For instance, each home (foreign)-currency-denominated bond is issued at a price $q_{t}\left(q_{t}^{*}\right)$ at the beginning of period $t$ and promises a delivery of 1 unit of home (foreign) currency at the end of the period. Since no overdraft is allowed on reserve accounts, the purchase of bonds faces a cash-in-advance constraint. Then, asset market closes and these financial transactors move to the non-tradable goods market, where credit buyers purchase goods using within-period IOUs. All such credit will be cleared by fiat currency through financial intermediaries at the end of the period.

Now, let us turn to the tradable goods market. After the cash is evenly distributed, each shopper faces with two itineraries, which we call itinerary 1 and itinerary 2. Along itinerary 1 , shoppers travel to the domestic tradable goods market, while itinerary 2 leads them to the foreign tradable goods market. Let $1-\alpha_{t}$ denote the fraction of shoppers who follow itinerary 1 and $\alpha_{t}$ the fraction who take itinerary 2 , where $\alpha_{t} \in[0,1]$ is a random variable. Note that, $\alpha_{t}$ can be interpreted as a natural index of openness and $1-\alpha_{t}$ is the degree of home-bias in 
consumption basket ${ }^{2}$. Economic theories have suggested that the impact of a monetary policy across countries depends on the openness of the economy.

Next, the household chooses the number of working hours assigned to the traded goods sector $\left(L_{r t}\right)$ and non-traded goods sector $\left(L_{n t}\right)$, respectively. The total labor supply of the representative household in period $t$ is $L_{t}$, where $L_{t}=L_{r t}+L_{n t}$. Labor is assumed to be internationally immobile. Then, workers in the non-traded goods sector produce output and sell each unit at a price $P_{n t}$ in exchange for IOUs, while workers in the traded sector hands out goods at $P_{r t}$ for money. Later on, credits clear and bonds pay off. All residual balances and trade receipts are collected and possessed by the financial transactors in each market, respectively. Immediately after that, financial transactors are randomly relocated by nature. A financial transactor who is at a given location at the end of the period will be allocated to the other location with probability $\pi$, and stay in the same location with probability $1-\pi$, where $\pi \in(0,1)$. Note that $\pi$ determines how fast the impacts of monetary policy are distributed within an economy and across countries. We assume that a zero-profit trade intermediary exists, which helps to implement currency exchanges. Such currency conversion is costless and can be done instantly by this intermediary according to the prevailing market exchange rate. This assumption implies that shoppers only need to hold home currency when walking around in the goods market.

\subsection{The Goods Market}

Two sectors of production exist in each economy, the tradable goods market and non-tradable goods market. Labor is the only factor that is employed to produce goods, that is

$Y_{i t}=A_{t} \cdot L_{i t}^{\theta}$

$Y_{i t}^{*}=A_{t}^{*} \cdot L_{i t}^{* \theta}$

where $i=n, r$, denoting the non-traded and traded goods sector, respectively. Note that, $A_{t}\left(A_{t}^{*}\right)$ is the labor productivity shock in the home (foreign) country, which is universally identical for all workers in that country. Breaking up a country's products into two dichotomous categories is relevant for at least three reasons. First, non-tradable goods take a substantial share of aggregate consumption baskets. Secondly, its presence helps to explain the volatility of nominal exchange rates. Thirdly, with non-tradables, consumption levels are not necessarily equalized across countries in response to some aggregate productivity shocks, or move in a synchronized fashion. That implies productivity shocks could exert distinct impacts on consumption across countries. It follows that nominal exchange rates are tied down by traded goods in equilibrium.

\section{The Household's Problem}

A representative household maximizes its expected intertemporal utility:

$$
E_{0}=\sum_{t=0}^{\infty} \beta^{t}\left[u\left(C_{t}\right)-v\left(L_{t}\right)\right]
$$

where $E_{0}$ represents the expectation conditional on information available at time $0, \beta$ is the time discount factor, $C_{t}$ denotes the consumption bundle in period $\mathrm{t}$ and $L_{t}$ is amount of the working time. We assume that $u(\cdot)$ is strictly increasing, strictly concave, twice differentiable, with $u^{\prime}(0)=\infty$. And $v(\cdot)$ is increasing, strictly convex, and twice differentiable, with $v^{\prime}(0)=\infty$ and $v^{\prime}(1)=\infty$.

The composite consumption $C$ is defined as follows:

$$
C=\left[\mu^{\frac{1}{\phi}} C_{r}^{\frac{\phi-1}{\phi}}+(1-\mu)^{\frac{1}{\phi}} C_{n}^{\frac{\phi-1}{\phi}}\right]^{\frac{\phi}{\phi-1}}
$$

where $C_{r}$ and $C_{n}$ represent the consumption of tradable and non-tradable goods, respectively, $\phi$ corresponds to the intratemporal elasticity of substitution between these two types of goods, and $\mu \in[0,1]$ is the relative weight that households put on tradable goods. This parameter is allowed to vary across countries. Similarly, the tradable goods basket $C_{r}$ is further composed by home-made goods $C_{h}$, and foreign goods $C_{f}$. That is,

$$
C_{r}=\left[\alpha^{\frac{1}{\eta}} C_{f}^{\frac{\eta-1}{\eta}}+(1-\alpha)^{\frac{1}{\eta}} C_{h}^{\frac{\eta-1}{\eta}}\right]^{\frac{\eta}{\eta-1}}
$$

where $\eta>1$ is the intratemporal elasticity of substitution between home and foreign tradable goods, $\alpha$ denotes the share of foreign tradable goods and $1-\alpha$ characterizes the home bias in consumption. 
At the same time, the formulated maximization problem for a representative household is subject to other constraints, such as:

$$
M_{t}^{c}+M_{t}^{r} \leq M_{t}
$$

The financial transactors located between $[0,1]$ must abide by the following budget constraint:

$$
\begin{aligned}
& q_{t} B_{h t+1}+S_{t} q_{t}^{*} B_{f t+1} \leq M_{t}^{r}+B_{h t}+S_{t} B_{f t} \\
& q_{t} B_{h t+1}+S_{t} q_{t}^{*} B_{f t+1}+P_{n t} C_{n t}+M_{n, t+1}+T_{t} \leq M_{t}^{r}+B_{h t}+S_{t} B_{f t}+P_{n t} A_{t} L_{n t}^{\theta}
\end{aligned}
$$

where $M_{j t+1}(j=n, r)$ represents the amount of money held by the financial transactors in market $j$ at the end of period $t$, but before the relocation, $T_{t}$ the lump-sum taxes paid by the household in period $t$, and $S_{t}$ the nominal exchange rate (domestic currency price of 1 unit of foreign currency). In this model, traded goods are priced in the producer's currency, while the non-traded goods prices are denominated in the consumers' currency.

The financial transactors in $[1,2]$ should satisfy the cash-in-advance constraints in the traded goods market as well:

$\left(1-\alpha_{t}\right) P_{r t} C_{h t} \leq\left(1-\alpha_{t}\right) M_{t}^{c}$

$\alpha_{t} S_{t} P_{r t}^{*} C_{f t} \leq \alpha_{t} M_{t}^{c}$

The above two cash constraints can be combined into the following

$$
\begin{gathered}
\left(1-\alpha_{t}\right) P_{r t} C_{h t}+\alpha_{t} S_{t} P_{r t}^{*} C_{f t} \leq M_{t}^{c} \\
\left(1-\alpha_{t}\right) P_{r t} C_{h t}+\alpha_{t} S_{t} P_{r t}^{*} C_{f t}+M_{r, t+1} \leq M_{t}^{c}+P_{r t} A_{t} L_{r t}^{\theta}
\end{gathered}
$$

Let $\bar{M}_{t+1}^{c}$ and $\bar{M}_{t+1}^{r}$ denote the money supply in tradable and non-tradable goods market, respectively, after all the transactions are implemented according to the household's instructions, but before financial transactors are relocated. Then

$$
\bar{M}_{t+1}^{r}=(1-\pi) \bar{M}_{n, t+1}+\pi \bar{M}_{r, t+1} \quad \bar{M}_{t+1}^{c}=\pi \bar{M}_{n, t+1}+(1-\pi) \bar{M}_{r, t+1}
$$

We are able to rewrite the above problem in a scaled form. That is deflating the appropriate nominal variables by the quantity of money in the tradable goods market $\bar{M}_{r t}$ dropping time subscripts, (e.g. $p_{n t}=\frac{P_{n t}}{\bar{M}_{r t}}$ and $\left.e_{t}=S_{t} \frac{\bar{M}_{r t}^{*}}{\bar{M}_{r t}}\right)$, using primes ", " to denote variables dated $t$ and superscripts " - " to denote variables dated $t-1$. Let $z_{j t}(j=n, r)$ indicate the gross growth rate in the money stock in market $j$ and $V\left(m_{n}, m_{r}, A, \gamma, z_{r}\right)$ denote the household's value function in period $t .{ }^{5}$ Now, taking the initial conditions $\left\{m_{n 0}, m_{r 0}, e_{0}, l_{0}\right\}$ and sequence $\left\{m_{t}, p_{n t}, p_{r t}, e_{t}, q_{t}\right\}_{t \geq 0}$ as given, the household chooses sequences $\left\{c_{t}, l_{t}, b_{t}, m_{n, t+1}, m_{r, t+1}\right\}$ to solve the following dynamic programming problem:

$V\left(m_{n}, m_{r}, A, \gamma, z_{r}\right)=\max _{c_{t}, l_{t}, b_{t}, m_{n}^{\prime}, m_{r}^{\prime}}\left\{u(c)-v(l)+\beta E_{t}\left[V\left(m_{n}^{\prime}, m_{r}^{\prime}, A^{\prime}, \gamma^{\prime}, z_{r}^{\prime}\right)\right]\right\}$

subject to

$$
\begin{aligned}
& c=\left[\mu^{\frac{1}{\phi}} c_{r}^{\frac{\phi-1}{\phi}}+(1-\mu)^{\frac{1}{\phi}} c_{n}^{\frac{\phi-1}{\phi}}\right]^{\frac{\phi}{\phi-1}} \\
& c_{r}=\left[\alpha^{\frac{1}{\eta}} c_{f}^{\frac{\eta-1}{\eta}}+(1-\alpha)^{\frac{1}{\eta}} c_{h}^{\frac{\eta-1}{\eta}}\right]^{\frac{\eta}{\eta-1}} \\
& l=l_{n}+l_{r} \\
& q b_{h}^{\prime}+e q^{*} b_{f}^{\prime} \leq(1-\pi) m_{n}+\pi+b_{h}+e b_{f} \\
& q b_{h}^{\prime}+e q^{*} b_{f}^{\prime}+p_{n} c_{n}+m_{n}^{\prime} z_{r}^{\prime}+\tau \leq(1-\pi) m_{n}+\pi+b_{h}+e b_{f}+p_{n} A l_{n}^{\theta}
\end{aligned}
$$




$$
\begin{aligned}
& (1-\alpha) p_{r} c_{h}+\alpha e p_{r}^{*} c_{f} \leq \pi m_{n}+(1-\pi) \\
& (1-\alpha) p_{r} c_{h}+\alpha e p_{r}^{*} c_{f}+m_{r}^{\prime} z_{r}^{\prime} \leq \pi m_{n}+(1-\pi)+p_{r} A l_{r}^{\theta}
\end{aligned}
$$

Next, let me substitute the expression of $c$ into the utility function and let $\lambda_{1}, \lambda_{2}, \lambda_{3}$ and $\lambda_{4}$ denote the multipliers associated with constraints (6)-(9). The first-order conditions then imply that

$$
\begin{aligned}
& u^{\prime}\left(c_{h}\right)=\left(\lambda_{3}+\lambda_{4}\right)(1-\alpha) p_{r} \\
& u^{\prime}\left(c_{f}\right)=\left(\lambda_{3}+\lambda_{4}\right) \alpha e p_{r}^{*}
\end{aligned}
$$

Combining equation (12) and (13) yields

$$
e_{t}=\frac{1-\alpha_{t}}{\alpha_{t}} \cdot \frac{p_{r t}}{p_{r t}^{*}} \cdot \frac{u^{\prime}\left(c_{f t}\right)}{u^{\prime}\left(c_{h t}\right)}
$$

Then, assuming that the cash-in-advance constraint for traded goods binds, we can show

$$
\frac{p_{r t}}{p_{r t}^{*}}=\frac{(1-\pi)+\pi m_{n t}}{\left(1-\pi^{*}\right)+\pi^{*} m_{n t}^{*}} \cdot \frac{c_{h t}^{*}}{c_{h t}}
$$

To use the above expression for $e_{t}$ to study the empirical behavior of the nominal exchange rates, we make an additional assumption that the representative households have CRRA utility function. Then, by equation (3) and (4), the ratio of marginal utility of $c_{h}$ and $c_{f}$ is

$$
\frac{u^{\prime}\left(c_{f t}\right)}{u^{\prime}\left(c_{h t}\right)}=\left(\frac{\alpha_{t}}{1-\alpha_{t}} \cdot \frac{c_{h t}}{c_{f t}}\right)^{\frac{1}{\eta}}
$$

Inserting equation (14) and (15) into $e$, the long-run equilibrium value of the nominal exchange rates can be determined as

$$
e_{t}=\left(\frac{1-\alpha_{t}}{\alpha_{t}}\right)^{1-\frac{1}{\eta}} \cdot \frac{(1-\pi)+\pi m_{n t}}{\left(1-\pi^{*}\right)+\pi^{*} m_{n t}^{*}} \cdot \frac{c_{h t}^{*}}{c_{h t}} \cdot\left(\frac{c_{h t}}{c_{f t}}\right)^{\frac{1}{\eta}}
$$

Recall, that the general form of nominal exchange rates in the previous literature is written as

$$
e_{t}^{s}=\frac{m_{t}}{m_{t}^{*}} \cdot \frac{y_{t}^{*}}{y_{t}}
$$

where $e_{t}^{s}$ represents the exchange rate determined in a standard monetary model, and $y_{t}\left(y_{t}^{*}\right)$ the real national income in the Home (Foreign) country. Basically, the conventional model states that the nominal exchange rate is determined by the relative money stock and the relative output of two countries.

Thus, Equation (16) not only encompasses the existing monetary models of the exchange rate, but also incorporates some new embellishments, such as the degree of economic openness $(\alpha)$, the home-bias toward traded goods $(\eta)$ and the distributional effect of monetary policy shocks across countries $(\pi)$, where $\pi$ is an index locating between 0 and 1 . It measures how fast that a monetary policy shock diffuses within an economy and transmits across borders.

For a given $\gamma>0$, we take the derivative of $e_{t}$ with respect to $\pi$ by holding other parameters constant, we have $\frac{d e_{t}}{d \pi}<0$. It says after a contractionary money shock occurs in the Home country, the faster it distributes, the more the home currency appreciates. It is known that the monetary diffusion $(\pi)$ depends on many factors in the real economic world, including the soundness of financial system, the efficiency of central banks, and so on. Therefore, assigning an appropriate value to $\pi$ requires an overall evaluation of a country's monetary system and financial markets. 
By far, we have shown the cointegration between nominal exchange rates and economic fundamentals in a theoretical framework. In the next section, we turn to question the statistical robustness of this study by employing the panel dynamic OLS regression suggested by Mark and Sul (2001). To make the following analysis easier, we will consider a special case of equation (16), where $\pi=\pi^{*}=\frac{1}{2}$. That is,

$e_{t}=\left(\frac{1-\alpha_{t}}{\alpha_{t}}\right)^{1-\frac{1}{\eta}} \cdot \frac{m_{t}}{m_{t}^{*}} \cdot \frac{c_{h t}^{*}}{c_{h t}} \cdot\left(\frac{c_{h t}}{c_{f t}}\right)^{\frac{1}{\eta}}$

Obviously, equation (16) and (17) indicate a slight departure from the conventional exchange rate determination. They capture in a simple way the basic idea, that nominal exchange rates are not only associated with the underlying macro-fundamentals, such as the aggregate money stock, the aggregate consumption of tradable goods, the degree of economic openness and the distributional effect of monetary policy, but also closely connected to some micro features, including the intratemporal elasticity of substitution between Home and Foreign tradable goods and the bias toward home-made goods.

\section{The Statistical Testing of the Model}

\subsection{The Data}

The data set consists of monthly time series observations for the nominal exchange rates, the broad money supply (M3) and the real industrial production. The degree of openness $\left(\alpha_{k}\right)$ is measured by [(industrial imports + exports) / total industrial production], from 1985:M1 to 2005:M12 for six OECD countries, namely Canada, Denmark, Japan, Sweden, United Kingdom and the United States. In the following analysis, the value of industrial products in each country is regarded as their domestically-made tradable goods. All variables are constructed by taking the United States as the numeraire country. The data were extracted from the SourceOECD and U.S Federal Reserve St. Louis. All data are seasonally adjusted.

\subsection{Econometric Methodology}

The United States is regarded as the "numeraire", labeled as " 0 " country in the empirical study. Let $s_{k t}$ denote the $\log$ nominal exchange rate between country $k=1,2, \ldots 5$ and the "numeraire" country in time $t$. To simplify the analysis, equation (17) is used and rewritten into a log-form as:

$$
\widetilde{e}_{k t}=\log \left(e_{e t}\right)=\left(1-\frac{1}{\eta}\right) \times \log \frac{1-\alpha_{k t}}{\alpha_{k t}}+\log \frac{m_{k t}}{m_{t}^{*}}-\left\{\left(1-\frac{1}{\eta}\right) \log \left(c_{k t}^{h}\right)-\left[\log \left(c_{h t}^{*}\right)-\frac{1}{\eta} \log \left(c_{k t}^{f}\right)\right]\right\}
$$

where $c_{k t}^{h}$ represents country $k$ 's consumption of domestically produced tradable goods $\left(c_{h}\right)$ in period $t$. Then, let $x_{k t}$ denote the deviation of the exchange rate from its long-run equilibrium value, which is defined as

$x_{k t}=\widetilde{e}_{k t}-s_{k t}$

The econometric analysis focuses on panel estimation of the following equations:

$\Delta s_{k t}=\delta x_{k, t-1}+\varepsilon_{k t}$

$\varepsilon_{k t}=\varphi_{k}+\zeta_{t}+u_{k t}$

where $k$ indexes country $k$ in consideration, $\varphi_{k}$ indicates a country-specific effect, $\zeta$ represents a time-specific effect that allows us to explain a limited amount of cross-sectional dependence, and $u_{k t}$ is the residual idiosyncratic error. To control for the possible asymptotic bias, Mark and Sul (2001) suggest that, the current value and $h_{k}$ leads and lags of $\Delta x_{k t-1}$ should be included in the regression, that is

$\Delta s_{k t}=\varphi_{k}+\zeta_{t}+\delta x_{k, t-1}+\sum_{f=-h_{k}}^{h_{k}} \varepsilon_{k f} \Delta x_{k, t-1-f}+u_{k t}$

where $k=1,2, \ldots 5, t=h_{k}+2, \ldots, T-h_{k}+1$. Under the current econometric specifications, the null hypothesis is no cointegration exists between the nominal exchange rates and the macro-fundamentals, or 
equivalently $H_{0}: \delta=0$. Without the loss of generality, we initially let $\eta=1.1$. Then the cases where $\eta=1.15$ and $\eta=1.2$ are also examined.

The results of the panel dynamic OLS regression for the cointegration test are reported in Table 1, where the significance level is chosen at 5\%. The statistical result shows that the null hypothesis of no integration between the macro-funamentals and the nominal exchange rates is rejected, when the U.S dollar is selected as the numeraire currency. In addition, this result is robust to different values of $\eta$, the intratemporal elasticity of substitution between home and foreign tradable goods. This statistical test, therefore, provides a simple glimpse of the validity of this liquidity-exchange rate model.

\section{Conclusion}

Since the collapse of the Bretton Woods system, increasing attention has been focused on the links between the nominal exchange rates and macro fundamentals, suggested by the standard monetary theories of exchange rate determination. However, few of the previous studies have obtained satisfactory success. The "exchange rate determination" problem is far from being resolved.

Our paper is a reappraisal and also an extension of the previous literature. It tries to determine the exchange rates by taking liquidity effects into consideration. A symmetric two-country model incorporated with limited participation and tradable and non-tradable goods are constructed to examine the cointegration between exchange rates and other economic indicators.

The model results show the way in which the nominal exchange rates relate to a set of economic fundamentals, including the degree of economic openness, aggregate money stock, consumption of tradable goods, the home-bias toward domestic goods and in particular, the distributional effect of monetary policies across countries. Then, a panel dynamic OLS regression is applied to investigate the empirical fit of a special case of the model. The statistical testing results are found in favor of this model, a departure from the conventional monetary model of exchange rate determination.

The encouraging evidence obtained in this study also impels us to explore, in the future work, whether there is any economic value to the predictive power of economic fundamentals for nominal exchange rates.

\section{References}

Alvarez, F., Atkeson , A. \& Kehoe, P. (2002). Money, Interest Rates and Exchange Rates with Endogenously Segmented Markets. Journal of Political Economy, 110, 73-112.

Bernanke B. \& Blinder, A. (1992). The Federal Funds Rate and the Channels of Monetary Transmission. American Economic Review, 82, 901-21.

Chari, V. V., Kehoe, P. J. \& McGrattan, E. R. (1999). Sticky price models of the business cycle: Can the contract multiplier solve the persistence problem? Econometrica, 68 (5), 1151-1179.

Christiano, L.J. \& Eichenbaum, M. (1992c). Liquidity Effects, the Monetary Transmission Mechanism and Monetary Policy. Economic Perspectives, 16(6), 2-14.

Christiano, L. \& Eichenbaum, M. (1995). Liquidity Effects, Monetary Policy, and the Business Cycle. Journal of Money, Credit and Banking, 27, 1113-1136.

Clarida, R., Gali, J. \& Gertler, M. (2002). A Simple Framework for International Monetary Policy Analysis. Journal of Monetary Economics, 49 , 879-904.

Frenkel, J. A. (1976). A Monetary Approach to the Exchange Rate: Doctrinal Aspects and Empirical Evidence. Scandinavian Journal of Economics, 78(2), 200-224.

Fuerst, Timothy (1992). Liquidity, Loanable Funds, and Real Activity. Journal of Monetary Economics, 29, 3-24.

Grilli, V. \& Roubini, N. (1996). Liquidity Models in Open Economies: Theory and Empirical Evidence. European Economic Review, 40, 847-859.

Grossman, S. \& Weiss, L. (1983). A transactions-based model of the monetary transmission mechanism.. American Economic Review, 73:5, 871-880.

Hairault, Jean-Olivier, Patureau, L. \& Sopraseuth, T. (2004). Overshooting and the Exchange Rate Disconnect Puzzle: a reappraisal. Journal of International Money and Finance, 23, 615-643. 
Hau, H. (2002). Real Exchange Rate Volatility and Economic Openness: Theory and Evidence. Journal of Money, Credit and Banking, 34, 611-630.

Lucas, R. E. (1990). Liquidity and Interest Rates. Journal of Economic Theory, 50, 237-264.

MacDonald, R. \& Taylor, M. (1993) The Monetary Approach to the Exchange Rate. IMF Staff Papers, 40 (1), 89-107.

Mark, N. (1995). Exchange Rates and Fundamentals: Evidence on Long-horizon Predictability. American Economic Review, 85, 201-218.

Mark, N. \& Sul, D. (2001). Nominal Exchange Rates and Monetary Fundamentals Evidence from a Small Post-Bretton Woods Panel. Journal of International Economics, 53, 29-52.

Meese, R. \& Rogoff, K.(1983a). Empirical Exchange Rate Models of the Seventies. Do They Fit out of Sample? Journal of International Economics, 14, 3-24.

Obstfeld, M. \& Rogoff, K. (1995). Exchange Rate Dyanmics Redux. Journal of Political Economy, 103, 624-660.

Obstfeld, M. \& Rogoff, K. (2000). The Six Major Puzzles in International Macroeconomics: Is There a Common Cause? NBER Macroeconomics Annual, 15, S.339-390.

Sarantis, N. (1994). The monetary exchange rate model in the long run: An empirical investigation. Review of World Economics, 130:4, 698-711.

Schlagenhauf, D. \& Wrase, J. (1995). Liquidity and Real Activity in a Simple Open-economy Model. Journal of Monetary Economics, 35:3, 431-461.

Walsh, Carl E. (2005). Labor Market Search, Sticky Prices, and Interest Rate Policies. Review of Economic Dynamics, 8, 829-849.

Williamson, S. D. (2004a). Limited Participation, Private Money, and Credit in a Spatial Model of Money. Economic Theory, 24, 857-76.

Williamson, S. (2005). Limited Participation and the Neutrality of Money. Federal Reserve Bank of Richmond, Economic Quarterly, 91, 1-20.

\section{Notes}

Note 1 . The "liquidity effect" is a general term to describe the impact of monetary policy on the aggregate economy. In this paper, it particularly refers to the effect of monetary policy on financial markets.

Note 2. Obstfeld and Rogoff (2000) claim that by explicityly introducing costs of international trade, one can go far toward explainning a great number of the main empirical puzzles in international macroeconomics. It is easy to show that the effects of trade costs are isomorphic to the effects of home bias in preferences.

Note 3. Hau (2002) investigates the role of nontradeables for the international monetary transmission mechanism. Hairault and Sopraseuth (2004) decompose the empirical volatility of the real exchange rate into two components: the relative price of traded goods and the relative price of nontraded to traded goods across countries.

Note 4. How to specify preferences is important in any micro-founded model. Chari, Kehoe and McGrattan (1999) argue that preferences separable in consumption and leisure are necessary for explaining the high volatility in exchange rates.

Note 5. Since $m_{n}=\frac{M_{n}}{M_{r}}$, it is sufficient to include only the money growth factor in traded goods market in the current state vector.

\section{Appendix}

\section{The Method of Panel Dynamic OLS}

Let $\Delta \underline{s}_{k}=\left(\Delta \underline{s}_{1 k}, \Delta \underline{s}_{2 k}, \ldots \Delta \underline{s}_{T k}\right)^{\prime}$ and $\Delta s=\left(\Delta \underline{s}_{1}, \Delta \underline{s}_{2}, \ldots \Delta \underline{s}_{N}\right)^{\prime}$ be the vectors of the observations on nominal exchange rate, $\underline{x}_{k}=\left(\underline{x}_{1 k}, \underline{x}_{2 k}, \ldots \underline{x}_{T-1 k}\right)^{\prime}$ be the $(T-1) \times 1$ vector of observations on $x_{k t}$, for country $k$, $\underline{0}$ be a $(T-1) \times 1$ vector of zeros, $\underline{\imath}$ be a $(T-1) \times 1$ vector of ones, $I$ a $T-1$ dimensional identity matrix, $\underline{z}_{k t}=\left(\Delta x_{k, t-1-h_{k}}, \ldots \Delta x_{k, t-1+h_{k}}\right), z_{k}=\left(z_{1 k}, \ldots z_{T k}\right)$ and 


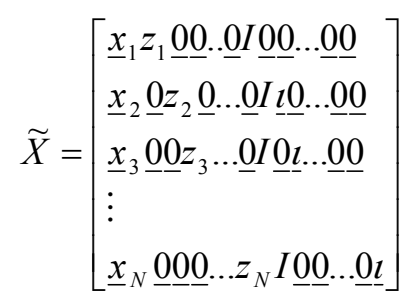

The panel dynamic OLS estimator of $\delta$, is the first element of the vector $\left(\widetilde{X}^{\prime} \widetilde{X}\right)^{-1} \tilde{X}^{\prime}(\Delta \bar{s}$, ). Mark and Sul (1999) show that, as $T \rightarrow \infty, N \rightarrow \infty$.

$$
\sqrt{N} T \cdot(\hat{\delta}-\delta) \sim N(\underline{0}, 2 \widetilde{V})
$$

where $\hat{\delta}$ is the estimator of $\delta$ and $\widetilde{V}$ is consistently estimated by $\widetilde{V}_{N T}=\widetilde{B}_{N T}^{-1} \widetilde{A}_{N T}^{-1} \widetilde{B}_{N T}^{-1}$. Note that $\widetilde{B}_{N T}=\frac{1}{N T^{2}} \sum_{k=1}^{N} \sum_{t=1}^{T} \widetilde{x}_{k t-1} \widetilde{x}_{k t-1}^{\prime}, \widetilde{A}_{N T}=\frac{1}{N T^{2}} \sum_{k=1}^{N} \hat{\Omega}_{k}^{2} \sum_{t=1}^{T} \tilde{x}_{k t-1} \tilde{x}_{k t-1}^{\prime}$ and $\hat{\Omega}_{k}^{2}$ is an estimate of the long run variance of $u_{k t}$.

Table 1. Panel Dynamic OLS Results

\begin{tabular}{|c|c|c|c|c|c|}
\hline \multirow{3}{*}{$\begin{array}{c}* \\
\text { Fundamentals } \\
\text { Macro-fundamentals }\end{array}$} & Numeraire & Intratemporal Elasticity & $H_{0}$ & STD of $\delta$ & P-Value \\
\cline { 3 - 6 } & United States & $\eta$ & 0.013 & 0.00373 & 0.039 \\
\cline { 3 - 7 } & & $\eta=1.1$ & 0.020 & 0.00301 & 0.041 \\
\cline { 3 - 7 } & & $\eta=1.15$ & 0.018 & 0.00404 & 0.032 \\
\hline
\end{tabular}

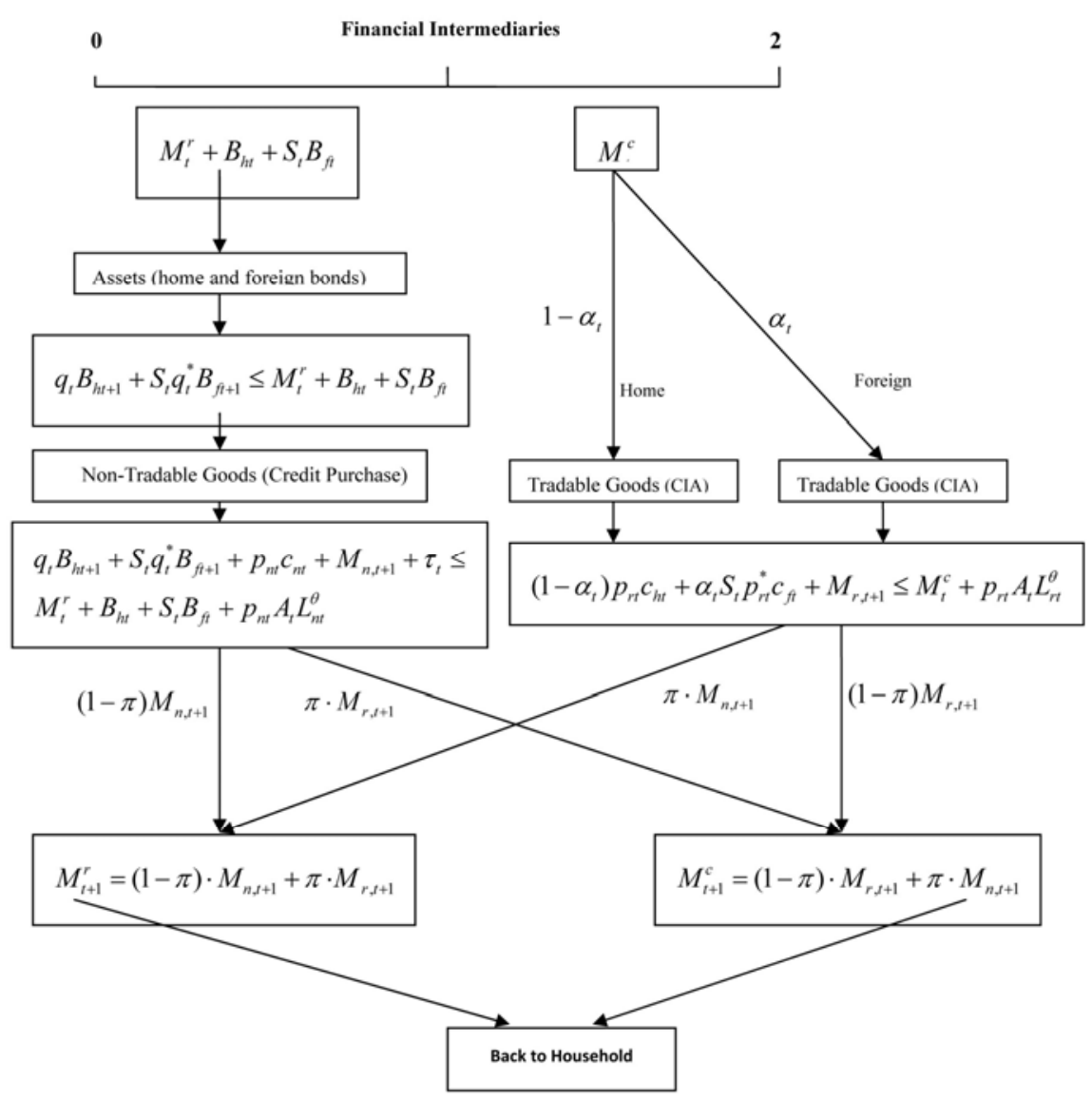

Figure 1. The Timings 